\title{
Endothelial cell density and corneal graft thickness following excimer laser vs. femtosecond laser-assisted penetrating keratoplasty-a prospective randomized study
}

\author{
Gábor Tóth $^{1,2}$ (D) Teona Butskhrikidze ${ }^{1} \cdot$ Berthold Seitz $^{1} \cdot$ Achim Langenbucher $^{3} \cdot$ Tobias Hager $^{1}$ • \\ Elina Akhmedova ${ }^{1}$ • Moatasem El-Husseiny ${ }^{1}$ • Nóra Szentmáry ${ }^{1,2}$
}

Received: 25 July 2018 /Revised: 31 January 2019 / Accepted: 9 February 2019 / Published online: 21 February 2019

(C) The Author(s) 2019

\begin{abstract}
Purpose The study aims to compare the impact of non-mechanical excimer laser-assisted (EXCIMER) and femtosecond laserassisted (FEMTO) trephinations on graft endothelial cell density (ECD) and graft thickness before and after suture removal following penetrating keratoplasty (PK).

Methods The inclusion criteria for this prospective, randomized, clinical study were as follows: (1) surgeries performed by one surgeon; (2) primary central PK; (3) keratoconus (KC) or Fuchs' dystrophy (FUCHS); (4) no previous intraocular surgery; (5) graft oversize, $0.1 \mathrm{~mm}$; and (6) 16-bite double-running suture. In 68 eyes of 68 patients (mean age: $53.3 \pm 19.8$ years), PK was performed using either 193-nm MEL70 excimer laser ("EXCIMER": 17 KC, 18 FUCHS) or 60-KHz femtosecond laser ("FEMTO": 17 KC, 16 FUCHS) trephination. Specular microscopy (EM 3000) and pachymetry (EM 3000; Pentacam HR; Casia SS-1000) were performed before removing the first suture (11.4 \pm 1.9 months) and after removing the second suture (22.6 \pm 3.8 months), but before any additional ophthalmic surgery.

Results ECD did not differ significantly $(P \geq 0.436)$ between EXCIMER and FEMTO either with "all-sutures-in" (1887 \pm 409 vs. $1886 \pm 438)$ or with "all-sutures-out" $(1703 \pm 379$ vs. $1737 \pm 362)$. Central corneal thickness and corneal thickness at the thinnest point of the cornea did not differ significantly between EXCIMER and FEMTO either with all-sutures-in $(P \geq 0.096$ and $P \geq 0.653$ ) or with all-sutures-out ( $P \geq 0.636$ and $P \geq 0.717$ ).

Conclusions EXCIMER and FEMTO trephinations from the epithelial side seem to have no disadvantages regarding endothelial cell loss after PK, and both surgical procedures are safe for the endothelium. A larger sample size and longer follow-up are needed to evaluate the long-term impact of EXCIMER and FEMTO trephinations on ECD.
\end{abstract}

Keywords Excimer $\cdot$ Femtosecond $\cdot$ Laser $\cdot$ Keratoplasty $\cdot$ Endothelium $\cdot$ Graft thickness

Drs. Gábor Tóth and Teona Butskhrikidze contributed equally as co-first authors to this manuscript.

Gábor Tóth

gabortothgabor@gmail.com

1 Department of Ophthalmology, Saarland University Medical Center, Kirrberger Str. 100, 66424 Homburg/Saar, Germany

2 Department of Ophthalmology, Semmelweis University, Mária utca 39, Budapest 1085, Hungary

3 Experimental Ophthalmology, Saarland University, Kirrberger Str. 100, 66424 Homburg/Saar, Germany

\section{Introduction}

Until the last decade, penetrating keratoplasty (PK) was the only treatment option to restore corneal clarity. Thereafter, lamellar keratoplasty techniques have in part replaced PK in keratoconus (KC) and Fuchs' endothelial dystrophy (FUCHS). Nevertheless, PK is still the most commonly performed full-thickness corneal transplantation for $\mathrm{KC}$ and FUCHS with stromal scarring [1].

Non-mechanical excimer laser-assisted (EXCIMER) trephination was introduced by Naumann in 1989. EXCIMER trephination yields significantly better refractive outcome than does motor trephination, particularly lower postoperative astigmatism, higher degree of topographic regularity, and better visual acuity $[2,3]$. 
Femtosecond laser-assisted (FEMTO) PK was introduced into clinical practice by Price in 2005 [4]. The lower pulse energy of the FEMTO may reduce surgically induced trauma, as a higher frequency of ultrashort pulses during tissue-laser interaction produces a very high energy density in the focus and minimizes thermal damage in the surrounding tissues [5].

In respect of graft survival and transparency, graft endothelial cell density (ECD) and quality and related changes in corneal thickness are crucial following PK [1].

ECD decreases with age, at a rate of $0.6 \%$ per year in healthy corneas [1]. The rate of endothelial cell loss (ECL) is accelerated after corneal transplantation. Bourne et al. reported $7.8 \%$ year ECL from 3 to 5 years, $4.2 \%$ year ECL from 5 to 10 years, and $0.2 \%$ year ECL between 10 and 15 years after PK $[6,7]$.

Following PK, postoperative ECL may be influenced by many factors, such as preoperative donor ECD and graft diameter, donor age, organ culture conditions, immune reactions, and surgical trauma. Endothelial cell protection during surgery increases the postoperative ECD. Different surgical techniques may also affect postoperative ECD. Development of gentle trephination methods for corneal transplantation and decreasing the rate of mechanical injuries during the surgery are crucial for graft survival [8].

Earlier studies comparing ECL after EXCIMER and mechanical trephinations, as well as FEMTO and mechanical trephinations, have shown that EXCIMER and FEMTO have no adverse effects on the graft endothelium compared to mechanical trephination, respectively [9-12].

The primary objective of this study was to compare the impact of non-mechanical EXCIMER and FEMTO trephinations on graft ECD and graft thickness before and after suture removal following PK. The secondary objective was to assess the impact of diagnosis (KC vs. FUCHS) on graft ECD and graft thickness before and after suture removal following PK.

\section{Patients and methods}

\section{Patients}

In this prospective, randomized, clinical, single-center study, patients with the diagnosis of KC or FUCHS undergoing PK were randomly assigned from the waiting list of the LIONS Cornea Bank Saar-Lor-Lux, Trier/Westpfalz, Germany, to two different methods of corneal trephination (EXCIMER and FEMTO). Assignments were made between January 2012 and December 2013 using a random-number table by the study nurse. All patients signed an informed consent form. The study was approved by the Ethics Committee of Saarland University, Germany (number 201/11).

Neither the patient, the surgeon, nor other team members could influence the assignment. However, patients were informed the day before surgery, which trephination technique was going to be performed and they could withdraw their informed consent during the complete time of the study. But no patient refused to participate. Only one eye of each patient was included. All surgical procedures were performed by one surgeon (BS), under general anesthesia.

For the present study, the exclusion criteria were previous ocular surgery, rejection reaction following PK, and simultaneous cataract or other surgery. Therefore, in the present study, 68 eyes of 68 patients ( 23 female and 45 male) undergoing PK were included. The EXCIMER group ( 35 eyes) consisted of 17 eyes with KC and 18 eyes with FUCHS. The FEMTO group (33 eyes) consisted of 17 eyes with $\mathrm{KC}$ and 16 eyes with FUCHS.

\section{Trephination and suturing techniques}

EXCIMER trephination was performed using a 193-nm excimer laser MEL70 (Carl Zeiss Meditec, Jena, Germany) along with metal masks at a $25-\mathrm{Hz}$ repetition rate and $1.2-\mathrm{mm}$ spot diameter. For donor trephination from the epithelial side by using the EXCIMER, a curved circular metal aperture mask (diameter, $8.1 \mathrm{~mm}$ in $\mathrm{KC}$ and $7.6 \mathrm{~mm}$ in FUCHS; central opening, $3.0 \mathrm{~mm}$ for centration; thickness, $0.5 \mathrm{~mm}$; weight, $0.173 \mathrm{~g}$; eight orientation teeth, $0.15 \times 0.3 \mathrm{~mm}$ ) was positioned on a corneoscleral button (16-mm diameter) fixed in an artificial anterior chamber under microscopic control. After perforation, the remaining stromal lamellae and Descemet's membrane were cut with curved corneal microscissors. The donor oversize was $0.1 \mathrm{~mm}$ in all cases. For recipient trephination, a corresponding circular metal mask was used (diameter, $12.9 \mathrm{~mm}$; central opening, $8.0 \mathrm{~mm}$ for $\mathrm{KC}$ and $7.5 \mathrm{~mm}$ for FUCHS; thickness, $0.5 \mathrm{~mm}$; weight, $0.29 \mathrm{~g}$; eight orientation notches, $0.15 \times 0.3 \mathrm{~mm}$ ). The laser beam was guided automatically along the edge of the mask without ablating the central cornea. After focal corneal perforation, the remaining deep stromal lamellae and Descemet's membrane were cut with curved corneal microscissors.

FEMTO trephination was performed using a $60-\mathrm{KHz}$ IntraLase $^{\mathrm{TM}}$ femtosecond laser (Abbott Medical Optics, Abbott Park, IL, USA). The mushroom profile (8.5-mm upper and $7.5-\mathrm{mm}$ lower diameters) was used in patients with $\mathrm{KC}$, and the top-hat profile (7.5-mm upper and $8.5-\mathrm{mm}$ lower diameters) was used in patients with FUCHS. In all cases, we used $0.1 \mu \mathrm{J}$ less energy than the maximum energy in the posterior side cut, $0.5 \mu \mathrm{J}$ less energy than the maximum energy in the anterior side cut, and $0.4 \mu \mathrm{J}$ less energy than the maximum energy in the ring lamellar cut (range 2.3-2.9 $\mu \mathrm{J}$ ). The eight alignment incisions in both the donor and recipient were created as follows: energy, $1.5 \mu \mathrm{J}$; length, 1000- $\mu \mathrm{m}$ width, $50 \mu \mathrm{m}$; spot separation, $6 \mu \mathrm{m}$; line separation, $6 \mu \mathrm{m}$; and layer separation, $5 \mu \mathrm{m}$. The radial offsets were +2 in all recipients (i.e., all the alignment incisions were outside the 
trephination) and -2 in all donors (i.e., all the alignment incisions were inside the trephination). On the anterior side cuts, the spot separation and layer separation were both $3 \mu \mathrm{m}$; in the ring lamellar cut (spiral pattern), the tangential spot separation was $5 \mu \mathrm{m}$ and the radial spot separation was $4 \mu \mathrm{m}$; and on the posterior side cut, the spot separation was $3 \mu \mathrm{m}$ and the layer separation was $2 \mu \mathrm{m}$. The depth of the lamellar cut of the donor and recipient was $2 / 3$ of the mean corneal thickness of the graft and recipient's eye, respectively. All side cut diameters (anterior and posterior side cuts) were $0.1 \mathrm{~mm}$ larger than the resulting diameter, thus overlapping each other. The donor cornea was placed into an artificial anterior chamber (Polytech, Roßdorf, Germany) to achieve trephination from the epithelial side. Each laser procedure requires a disposable glass interface, which applanates the cornea during the laser procedure. For laser trephination of the recipient's cornea, the eye was fixated by means of a vacuum suction ring. The glass cone interface was placed within the suction ring so that the cornea was applanated. After laser trephination, the corneal button was removed with forceps and a spatula under microscopic control. If necessary, microscissors were used to complete the incision [13].

In all patients, a peripheral iridotomy was performed at the 12-o'clock position. After temporary fixation of the donor button in the recipient bed with eight interrupted sutures, a permanent wound closure was achieved using a 16-bite double-running diagonal cross-stitch suture (10-0 nylon) described by Hoffmann [14]. We attempted to suture as deep as $90 \%$ of the total corneal thickness in both groups in all eyes. The eight interrupted sutures were placed at the site of the orientation teeth with the EXCIMER and at the site of the alignment incisions with the FEMTO as well as possible. In cases of wound gaping or graft override, additional interrupted sutures were used to ensure proper donor-host alignment at the end of surgery.

\section{Methods and main outcome measures}

ECD (EM 3000 specular microscopy; Tomey, Erlangen, Germany), central corneal thickness (CCT; three devices: Pentacam HR Scheimpflug tomography, Wetzlar, Germany; Casia SS-1000 swept-source Fourier domain OCT, Tomey, Erlangen-Tennenlohe, Germany; EM 3000, Tomey), and corneal thickness at the thinnest point of the cornea (TCT; two devices: Pentacam HR and Casia SS-1000) were measured before removing the first suture (first follow-up, "all-suturesin" $[11.4 \pm 1.9$ months, range 3-19 months]) and after removing the second suture (second follow-up, "all-sutures-out" [22.6 \pm 3.8 months, range 19-38 months]), but before any additional surgical intervention. Specular microscopic images acquired using EM3000 were processed using the automatic cell analysis software EM-1100 (software version 1.5,
Tomey). We used the measurement results for analysis, if at least 120 cells were measured by the software.

\section{Statistical analysis}

The primary analysis is comparison of EXCIMER vs. FEMTO before removing of the first suture with respect to ECD (cells $/ \mathrm{mm}^{2}$ ). All other comparisons are secondary analyses and have to be interpreted exploratively. With respect to primary analysis and assuming a clinically relevant group difference of 300 cells $/ \mathrm{mm}^{2}$, the following sample size calculation holds: a sample size of 35 in each group will have $80 \%$ power to detect a difference in means of 300 cells $/ \mathrm{mm}^{2}$, assuming that the common standard deviation is 440 cells $/ \mathrm{mm}^{2}$ using a two-group $t$ test with a 0.05 two-sided significance level (nQuery Advisor, version 7.0, Statistical Solutions, Cork, Ireland).

Statistical analysis was performed using IBM SPSS Statistics for Windows, version 19.0 (IBM Corp., Armonk, NY, USA).

\section{Results}

The details of the patients and donors (all organ cultured) undergoing EXCIMER or FEMTO trephination are displayed in Table 1 . The mean age at the time of surgery was $53.3 \pm$ 19.8 years (range 17-86 years).

The ECD, CCT, and TCT values, measured using EM3000, Pentacam, and Casia SS-1000 in patients with KC and FUCHS undergoing EXCIMER or FEMTO trephination, are displayed at Tables 2 and 3.

Comparing EXCIMER vs. FEMTO trephination for the complete study population, no significant difference was observed in any of the analyzed values comparing the allsutures-in and all-sutures-out time points (Table 2). In this analysis, CCT and TCT did not correlate significantly with ECD, either with all-sutures-in $(r \leq 0.267, P \geq 0.056$ and $r \leq$ $0.120, P \geq 0.430)$ or with all-sutures-out ( $r \leq 0.230, P \geq 0.101$ and $r \leq 0.244, P \geq 0.099$ ).

No significant difference was observed when comparing ECD, CCT, or TCT at any of the time points between patients with $\mathrm{KC}$ and FUCHS $(P \geq 0.145)$ (Table 3$)$.

However, ECD $(P=0.037)$ was significantly lower and CCT (Pentacam; $P=0.021$ ) and TCT (Pentacam and Casia SS-1000; $P=0.010$ and 0.008 ) were significantly higher in patients with $\mathrm{KC}$ with all-sutures-out than in those with allsutures-in. CCT (Pentacam and Casia SS-1000; $P=0.030$ and 0.011 ) and TCT (Pentacam and Casia SS-1000; $P=0.033$ and 0.001 ) were significantly higher in patients with FUCHS with all-sutures-out than in those with all-sutures-in (Table 3). 
Table 1 Details of recipients and donors undergoing EXCIMER or FEMTO trephination $(n=68$; mean \pm SD (range))

\begin{tabular}{llll}
\hline & EXCIMER $(n=35)$ & FEMTO $(n=33)$ & $P$ value \\
\hline Recipient characteristics & & & \\
Mean age at the time of surgery (years) & $52.9 \pm 20.4$ & $53.8 \pm 19.6$ & 0.936 \\
Time of first follow-up (months) & $11.1 \pm 2.5$ (range 3-19) & $11.9 \pm 1.4$ (range 9-15) & 0.435 \\
Time of second follow-up (months) & $22.8 \pm 4.4$ (range 19-35) & $22.4 \pm 3.4$ (range 20-38) & 0.139 \\
Donor graft characteristics & & & \\
Postmortem time (h) & $16.4 \pm 14.5$ & $13.0 \pm 11.8$ & 0.310 \\
Preservation time (days) & $18.7 \pm 6.1$ & $17.2 \pm 4.1$ & 0.301 \\
Preoperative donor ECD (cells $\left./ \mathrm{mm}^{2}\right)$ & $2461 \pm 322$ & $2453 \pm 274$ & 0.961 \\
\hline
\end{tabular}

ECD endothelial cell density

Table 2 Postkeratoplasty endothelial cell density (ECD), central corneal thickness (CCT), and thinnest corneal thickness (TCT), before ("all-suturesin") and after ("all-sutures-out") suture removal (SR), by using EXCIMER or FEMTO trephination ( $n=68$; mean \pm SD (range))

\begin{tabular}{|c|c|c|c|}
\hline & $\begin{array}{l}\text { Before SR (follow-up; } 11.4 \pm 1.9 \text { months, } \\
\text { range 3-19 months) }\end{array}$ & $\begin{array}{l}\text { After SR (follow-up; } 22.6 \pm 3.8 \text { months, } \\
\text { range } 19-38 \text { months) }\end{array}$ & $P$ value \\
\hline \multicolumn{4}{|l|}{ EXCIMER $(n=35)$} \\
\hline $\operatorname{ECD}\left(\right.$ cells $\left./ \mathrm{mm}^{2}\right)$ & $1887 \pm 409(1014-2532)$ & $1703 \pm 379(1029-2485)$ & 0.101 \\
\hline \multicolumn{4}{|l|}{$\mathrm{CCT}(\mu \mathrm{m})$} \\
\hline Pentacam & $519 \pm 39(448-593)$ & $552 \pm 56(401-672)$ & 0.334 \\
\hline Casia-SS & $515 \pm 44(434-610)$ & $546 \pm 51(467-674)$ & 0.231 \\
\hline EM-3000 & $520 \pm 43(438-576)$ & $544 \pm 66(439-736)$ & 0.756 \\
\hline \multicolumn{4}{|l|}{$\mathrm{TCT}(\mu \mathrm{m})$} \\
\hline Pentacam & $507 \pm 40(427-577)$ & $537 \pm 55(384-651)$ & 0.708 \\
\hline Casia-SS & $498 \pm 55(413-568)$ & $531 \pm 44(455-621)$ & 0.066 \\
\hline \multicolumn{4}{|l|}{ FEMTO $(n=33)$} \\
\hline $\mathrm{ECD}\left(\right.$ cells $\left./ \mathrm{mm}^{2}\right)$ & $1886 \pm 438(997-2540)$ & $1737 \pm 362(985-2283)$ & 0.497 \\
\hline \multicolumn{4}{|l|}{$\mathrm{CCT}(\mu \mathrm{m})$} \\
\hline Pentacam & $527 \pm 60(428-686)$ & $552 \pm 49(451-644)$ & 0.213 \\
\hline Casia-SS & $513 \pm 52(424-618)$ & $544 \pm 40(463-618)$ & 0.149 \\
\hline EM-3000 & $496 \pm 50(419-611)$ & $518 \pm 91(453-631)$ & 0.120 \\
\hline \multicolumn{4}{|l|}{$\mathrm{TCT}(\mu \mathrm{m})$} \\
\hline Pentacam & $509 \pm 56(417-665)$ & $539 \pm 46(439-629)$ & 0.088 \\
\hline Casia-SS & $486 \pm 51(384-611)$ & $532 \pm 40(457-613)$ & 0.078 \\
\hline \multicolumn{4}{|c|}{ Comparison between EXCIMER and FEMTO } \\
\hline$P$ value $-\mathrm{ECD}$ & 0.755 & 0.436 & \\
\hline \multicolumn{4}{|l|}{$P$ value $-\mathrm{CCT}$} \\
\hline Pentacam & 0.829 & 0.822 & \\
\hline Casia-SS & 0.792 & 0.636 & \\
\hline EM-3000 & 0.096 & 0.678 & \\
\hline \multicolumn{4}{|l|}{$P$ value $-\mathrm{TCT}$} \\
\hline Pentacam & 0.653 & 0.788 & \\
\hline Casia-SS & 0.763 & 0.717 & \\
\hline
\end{tabular}

No statistically significant difference was observed in any of the measurement values when comparing both the time points in the EXCIMER or FEMTO trephination groups or when comparing both trephination techniques $(P \geq 0.066)$

Pentacam: Pentacam HR Scheimpflug tomography, Wetzlar, Germany; Casia-SS: Casia SS-1000 swept-source Fourier domain OCT, Tomey, ErlangenTennenlohe, Germany; EM-3000: EM 3000 specular microscopy, Tomey, Erlangen, Germany 
Table 3 Postkeratoplasty endothelial cell density (ECD), central corneal thickness (CCT), and thinnest corneal thickness (TCT) in keratoconus (KC) and Fuchs' dystrophy (FUCHS) before ("all-sutures- in") and after ("all-sutures-out") suture removal (SR) and when comparing both the diagnosis groups at different time points $(n=68$; mean $\pm \mathrm{SD}$ (range))

Before SR (follow-up; $11.4 \pm 1.9$ months,

After SR (follow-up; $22.6 \pm 3.8$ months,

$P$ value range 3-19 months) range 19-38 months)

\begin{tabular}{|c|c|c|c|}
\hline \multicolumn{4}{|l|}{$\mathrm{KC}(n=34)$} \\
\hline $\mathrm{ECD}\left(\mathrm{cells} / \mathrm{mm}^{2}\right)$ & $1976 \pm 410(1045-2540)$ & $1795 \pm 303(1212-2318)$ & 0.037 \\
\hline \multicolumn{4}{|l|}{$\mathrm{CCT}(\mu \mathrm{m})$} \\
\hline Pentacam & $522 \pm 49(428-635)$ & $549 \pm 46(401-659)$ & 0.021 \\
\hline Casia-SS & $518 \pm 50(424-618)$ & $544 \pm 39(463-674)$ & 0.059 \\
\hline EM-3000 & $524 \pm 52(431-665)$ & $549 \pm 41(428-649)$ & 0.259 \\
\hline \multicolumn{4}{|l|}{$\mathrm{TCT}(\mu \mathrm{m})$} \\
\hline Pentacam & $505 \pm 50(419-580)$ & $525 \pm 35(447-599)$ & 0.010 \\
\hline Casia-SS & $493 \pm 58(384-658)$ & $528 \pm 32(457-589)$ & 0.008 \\
\hline \multicolumn{4}{|l|}{ FUCHS $(n=34)$} \\
\hline $\mathrm{ECD}\left(\right.$ cells $\left./ \mathrm{mm}^{2}\right)$ & $1844 \pm 396(997-2399)$ & $1652 \pm 423(985-2485)$ & 0.077 \\
\hline \multicolumn{4}{|l|}{$\mathrm{CCT}(\mu \mathrm{m})$} \\
\hline Pentacam & $523 \pm 53(448-686)$ & $557 \pm 59(451-672)$ & $\mathbf{0 . 0 3 0}$ \\
\hline Casia-SS & $507 \pm 44(434-613)$ & $549 \pm 54(467-650)$ & 0.011 \\
\hline EM-3000 & $522 \pm 53(443-681)$ & $558 \pm 56(473-668)$ & 0.082 \\
\hline \multicolumn{4}{|l|}{$\mathrm{TCT}(\mu \mathrm{m})$} \\
\hline Pentacam & $511 \pm 45(441-611)$ & $539 \pm 58(439-651)$ & 0.033 \\
\hline Casia-SS & $485 \pm 48(413-611)$ & $537 \pm 51(455-621)$ & 0.001 \\
\hline \multicolumn{4}{|c|}{ Comparison between $\mathrm{KC}$ and FUCHS } \\
\hline$P$ value - ECD & 0.249 & 0.145 & \\
\hline \multicolumn{4}{|l|}{$P$ value $-\mathrm{CCT}$} \\
\hline Pentacam & 0.938 & 0.742 & \\
\hline Casia-SS & 0.422 & 0.812 & \\
\hline EM-3000 & 0.856 & 0.845 & \\
\hline \multicolumn{4}{|l|}{$P$ value - TCT } \\
\hline Pentacam & 0.768 & 0.183 & \\
\hline Casia-SS & 0.521 & 0.496 & \\
\hline
\end{tabular}

Significant $P$ values are bold

Pentacam: Pentacam HR Scheimpflug tomography, Wetzlar, Germany; Casia-SS: Casia SS-1000 swept-source Fourier domain OCT, Tomey, ErlangenTennenlohe, Germany; EM-3000: EM 3000 specular microscopy, Tomey, Erlangen, Germany

\section{Discussion}

An important aspect of PK is to avoid injury to the corneal endothelial cells during trephination. Different trephination techniques may have different effects on the donor and host endothelium.

To our knowledge, this is the first clinical study comparing the effects of EXCIMER and FEMTO PK trephination on postoperative ECD and graft thickness in patients with $\mathrm{KC}$ and FUCHS.

This direct comparison is important because FEMTO trephination is typically completed with laser, whereas the incision has typically to be completed manually with scissors after EXCIMER trephination, because the laser trephination stops after aqueous humor enters the incision.
Among conventional trephination techniques from the epithelial side, the Hessburg-Barron vacuum trephine produces a $150-\mu \mathrm{m}$-wide damage zone [15], the Franceschetti manual trephine produces a 200- $\mu \mathrm{m}$-wide damage zone, and the Draeger motor trephine produces a $150-\mu \mathrm{m}$-wide damage zone from the graft border [16].

Complete FEMTO trephination was reported to produce a 220- $\mu$ m-wide denuded Descemet's membrane from the graft border [17], while EXCIMER trephination induced damage to only a few cell lines without denudation of Descemet's membrane [18].

Kim et al. did not find a significant difference in ECD in the graft center following FEMTO and vacuum trephinations, but FEMTO trephination seemed to be less harmful to the endothelial cells than vacuum trephination around the incision area [17]. 
Before first $(11.1 \pm 2.5$ months $)$ and after second suture removal (22.8 \pm 4.4 months), we observed $24 \%$ and $31 \%$ ECL following EXCIMER trephination, when compared to preoperative donor ECD. Schumacher et al. [19] reported that EXCIMER trephination causes less ECL than does motor trephination after 12 months $(24 \%$ vs. $36 \%)$ and after 24 months (37\% vs. 51\%). However, in a larger sample population, Seitz et al. did not find a difference in postoperative ECL between motor and EXCIMER trephinations [10].

In our study, for FEMTO trephination we observed 23\% ECL before first (11.9 \pm 1.4 months) and 29\% ECL after second suture removal (22.4 \pm 3.4 months). Birnbaum et al. reported 1 year after PK, $19.0 \%$ ECL after mushroom profile and 16.5\% ECL after top-hat profile FEMTO trephinations [11], and these values were - similar to ours - lower than those reported earlier by Patel et al. (34\%) who used a vacuum trephine [7].

The strength of this study is that only two well-defined corneal diseases were included. Donor trephination was performed using an artificial anterior chamber in both groups [20]. The endothelial cell layer was protected using viscoelastic substances during trephination, which facilitated $360^{\circ}$ perforation in FEMTO trephination, thereby reducing the need to use scissors during surgery.

In the present study, we did not find a significant difference in ECD or graft thickness between EXCIMER and FEMTO trephinations, either with all-sutures-in or all-sutures-out. Both trephination procedures using the laser beam seem to be safe for the central corneal endothelium and had no disadvantages regarding ECL compared to mechanical trephination after PK in earlier studies [10-12]. However, EXCIMER and FEMTO trephination may lead to different changes of the blood-aqueous barrier [21, 22], to elevation of prostaglandin [23] and free radical levels in the anterior chamber [24], which may also influence ECD in a different way in the longer term after PK [25]. Despite all this, there was no significant difference regarding ECL between EXCIMER and FEMTO trephination during follow-up. The effect of both trephination techniques on blood-aqueous barrier, prostaglandin, and free radical levels in the anterior chamber have to be further studied in the future.

Our primary objective was to compare ECD following EXCIMER and FEMTO trephination. The results of the comparison of ECD between the KC and FUCHS groups are secondary data obtained in this study. Similar to Seitz' [10] and Abbott's [26] results, we did not find a significant difference between patients with KC and FUCHS - either before or after suture removal - in postoperative ECD and graft thickness. Interestingly, we found a significant ECL between the allsutures-in and all-sutures-out time points in patients with $\mathrm{KC}$. This result is controversial, because according to the endothelial cell migration theory [27], patients with KC have less postoperative ECL after PK than do those with FUCHS. Moreover, we found a significant increase in CCT and TCT from before to after suture removal in both the $\mathrm{KC}$ and
FUCHS groups. Although we did not find a significant difference in ECD between the before and after suture removal time points in FUCHS, we saw a decreasing tendency of ECD. Therefore, the increase in CCT and TCT may be related to ECL in both the groups. The absence of significant ECL in FUCHS from the before to after suture removal time points and the absence of correlation between graft thickness (CCT and TCT) and ECD may be attributed to the small sample size and high standard deviation in this study.

The introduction of EXCIMER trephination in 1989 [2] and FEMTO trephination in 2005 [28] for corneal transplantation may have increased the surgery time and cost. Nowadays, with the use of modern EXCIMER systems, the necessity of additional time for EXCIMER trephination is no more than 5-10 min, when compared to that for HessburgBarron trephination. In addition to the primary investment and maintenance costs of lasers, the treatment package cost of FEMTO trephination may especially play a role in the overall costs of laser transplantation surgery. Nevertheless, in our opinion, owing to its better visual and refractive outcomes, EXCIMER trephination may retain or even increase its importance in corneal transplantation surgery in the future [3].

In conclusion, EXCIMER and FEMTO trephinations from the epithelial side seem to have no disadvantages regarding ECL after PK, and both surgical procedures are safe for the endothelium. A larger sample size and longer follow-up are needed to evaluate the long-term impact of EXCIMER and FEMTO trephinations on ECD following PK.

Acknowledgments Open access funding provided by Semmelweis University (SE). We thank Prof. Dr. Stefan Wagenpfeil, chairman of the Institute for Medical Biometry, Epidemiology and Medical Informatics of Saarland University, Homburg/Saar, Germany, for his support in the statistical analysis of our data.

Funding No funding was received for this research.

\section{Compliance with ethical standards}

Conflict of interest The authors declare that they have no conflict of interest.

Ethical approval All procedures performed in studies involving human participants were in accordance with the ethical standards of the institutional and/or national research committee and with the 1964 Helsinki declaration and its later amendments or comparable ethical standards.

Informed consent Informed consent was obtained from all individual participants included in the study.

Open Access This article is distributed under the terms of the Creative Commons Attribution 4.0 International License (http:// creativecommons.org/licenses/by/4.0/), which permits unrestricted use, distribution, and reproduction in any medium, provided you give appropriate credit to the original author(s) and the source, provide a link to the Creative Commons license, and indicate if changes were made. 
Publisher's note Springer Nature remains neutral with regard to jurisdictional claims in published maps and institutional affiliations.

\section{References}

1. Bourne WM, Nelson LR, Hodge DO (1997) Central corneal endothelial cell changes over a ten-year period. Invest Ophthalmol Vis Sci 38:779-782

2. Naumann GOH, Seitz B, Lang GK, Langenbucher A, Kus MM (1993) [193 excimer laser trepanation in perforating keratoplasty]. Report of 70 patients. Klin Monatsbl Augenheilkd 203:252-261

3. Seitz B, Langenbucher A, Kus MM, Küchle M, Naumann GOH (1999) Nonmechanical corneal trephination with the excimer laser improves outcome after penetrating keratoplasty. Ophthalmology 106:1156-1164

4. Price FW, Price MO (2008) Femtosecond laser shaped penetrating keratoplasty: one-year results utilizing a top-hat configuration. Am J Ophthalmol 145:210-214

5. Birnbaum F, Maier P, Reinhard T (2011) Perspectives of femtosecond laser-assisted keratoplasty. Ophthalmologe 108:807-816

6. Ing JJ, Ing HH, Nelson LR, Hodge DO, Bourne WM (1998) Tenyear postoperative results of penetrating keratoplasty. Ophthalmology 105:1855-1865

7. Patel SV, Hodge DO, Bourne WM (2005) Corneal endothelium and postperative outcomes 15 years after penetrating keratoplasty. Am J Ophthalmol 139:311-319

8. Langenbucher A, Seitz B, Nguyen NX, Naumann GOH (2002) Corneal endothelial cell loss after nonmechanical penetrating keratoplasty depends on diagnosis: a regression analysis. Graefe's arch. Clin Exp Ophthalmol 240:387-392

9. Seitz B, Langenbucher A, Naumann GOH (2011) Perspectives of excimer laser-assisted keratoplasty. Ophthalmologe 108:817-824

10. Seitz B, Langenbucher A, Nguyen NX, Kus MM, Küchle M, Naumann GOH (2001) Graft endothelium and thickness after penetrating keratoplasty, comparing mechanical and excimer laser trephination: a prospective randomised study. Graefe's arch. Clin Exp Ophthalmol 239:12-17

11. Birnbaum F, Wiggermann A, Maier PC, Böhringer D, Reinhard T (2013) Clinical results of 123 femtosecond laser-assisted penetrating keratoplasties. Graefes Arch Clin Exp Ophthalmol 251:95-103

12. Daniel MC, Böhringer D, Maier P, Eberwein P, Birnbaum F, Reinhard T (2016) Comparison of long-term outcomes of femtosecond laser-assisted keratoplasty with conventional keratoplasty. Cornea 35:293-298

13. El-Husseiny M, Seitz B, Langenbucher A, Akhmedova E, Szentmáry N, Hager T, Tsintarakis T, Janunts E (2015) Excimer versus femtosecond laser assisted penetrating keratoplasty in keratoconus and Fuchs dystrophy: intraoperative pitfalls. J Ophthalmol 645830

14. Hoffmann F (1976) Suture technique for penetrating keratoplasty. Klin Monatsbl Augenheilkd 169:584-590
15. Legeais JM, Parel JM, Simon G, Ren Q, Denham D (1993) Endothelial damage by the corneal Hessburg-Barron vacuum trephine. Refract Corneal Surg 9:255-258

16. Böhnke M, Draeger J, Niesmann U (1982) Effect of the cutting procedure on the vitality of corneal endothelium in donor material. Ophthalmic Res 14:459-465

17. Kim JH, Choi SK, Lee D (2009) The comparison of femtosceond laser-assisted penetrating keratoplasty with conventional surgery in terms of endothelial safety: ex vivo study using porcine eyes. Cornea 28:812-816

18. Koch JW, Lang GK, Naumann GOH (1991) Endothelial reactions to perforating and non-perforating excimer laser excisions in rabbits. Refract Corneal Surg 7:214-222

19. Schumacher M, Langenbucher A, Seitz B (2017) Development of endothelial cell density after penetrating keratoplasty in patients with Fuchs dystrophy or keratoconus - comparison of excimer laser and mechanical trephination. Klin Monatsbl Augenheilkd 234: 697-705

20. Resch MD, Zemova E, Marsovszky L et al (2015) In vivo confocal microscopic imaging of the cornea after femtosecond and excimer laser-assisted penetrating keratoplasty. J Refract Surg 31:620-626

21. Küchle M, Nguyen NX, Naumann GOH (1994) Aqueous flare following penetrating keratoplasty and in corneal graft rejection. Arch Ophthalmol 112:354-358

22. Küchle M, Nguyen NX, Seitz B, Langenbucher A, Naumann GOH (1998) Blood-aqueous barrier after mechanical or nonmechanical excimer laser trephination in penetrating keratoplasty. Am J Ophthalmol 125:177-181

23. Kiss HJ, Takács ÁI, Kránitz K, Sándor GL, Tóth G, Gilányi B, Nagy ZZ (2016) One-day use of preoperative topical nonsteroidal anti-inflammatory drug prevents intraoperative prostaglandin level elevation during femtosecond laser-assisted cataract surgery. Curr Eye Res 41:1064-1067

24. Tóth G, Sándor GL, Kleiner D, Szentmáry N, Kiss HJ, Blázovics A, Nagy ZZ (2016) Evaluation of free radical quantity in the anterior chamber following femtosecond-laser assisted capsulotomy. Orv Hetil 157:1880-1883

25. Murano N, Ishizaki M, Sato S, Fukuda Y, Takahashi H (2008) Corneal endothelial cell damage by free radicals associated with ultrasound oscillation. Arch Ophthalmol 126:816-821

26. Abott RL, Fine M, Guillet E (1983) Long-term changes in corneal endothelium following penetrating keratoplasty: a specular microscopy study. Ophthalmology 90:676-685

27. Reinhard T, Böhringer D, Hüschen D, Sundmacher R (2002) Chronic endothelial cell loss of the graft after penetrating keratoplasty: influence of endothelial cell migration from graft to host. Klin Monatsbl Augenheilkd 219:410-416

28. Steinert RF, Ignacio TS, Sarayba MA (2007) “Top hat"-shaped penetrating keratoplasty using the femtosecond laser. Am J Ophthalmol 143:689-691 